\title{
Factors Influencing Breast-Feeding Among Women in China
}

\section{Junzi Hea}

\begin{abstract}
Although a well-established association between breast-feeding and a range of positive health outcomes in children has been demonstrated, less attention has been paid under China circumstance, especially what factors will influence breast-feeding behavior among Chinese women from empirical perspective has not been explored yet. In this paper, survival analysis with duration model is applied to find out the main determinants. The well-known China Health and Nutrition Survey (CHNS) dataset fits for this study since it has plenty information about breast-feeding and children. Family income, age, education level, and maternity leave are found to be the main determinants which have significant effects on the breast-feeding behavior, also the gender of infant plays an important role which is for Chinese-specific cases. The opportunity cost for women with higher education level and higher income, especially in urban areas is so high that they have to shorten the duration of breastfeeding their children. The probability of breast-feeding her child is decreasing with the aging of mother.
\end{abstract}

\section{Keywords}

Breast-feeding behavior, main determinants, education level, income distribution, empirical analysis

In recent years, a considerable body of research has emerged which suggests that there can be substantial benefits attached to breast-feeding for the mother and child. The benefits are not only important to the physical well-being of mother and child but also are important at a psychological level as well. For infants, the most immediate benefit is bonding of mother and child. Also breast-feeding for four weeks is positively and statistically significantly associated with higher cognitive test scores, by around one tenth of a standard deviation (Borra, Iacovou, and Sevilla 2012). The physical benefits of breast-feeding for mothers are even more numerous than the psychological. These benefits include weight loss, cancer and osteoporosis prevention. People who were breast-fed as babies are less likely to be overweight or obese later in life. They may also be less prone to diabetes and perform better in intelligence tests. While with the modernization of society, there is a tendency that more and more mothers choose milk powder and then shorten the duration of breast-feeding. The reasons vary among different people, some moms have nipple paining problem while others are so busy with work that have no time to breastfeed their children long enough as they want to.

Although breast-feeding is the best source of nourishment for infants and young children and one of the most effective ways to ensure child health and survival, globally only an estimated $38 \%$ of infants are exclusively breast-fed for six months ${ }^{1}$. In China, the

aCentral University of Finance and Economics, Beijing, China

\section{Correspondent Author:}

Junzi He, 39 South College Road, Haidian District, Beijing, China, 100081 
average proportion of exclusive breast-feeding for infants in zero to six months in 2008 is only $27.6 \%$, with great efforts pushed by government and all the society, till 2013, it has been dramatically driven up to $58.5 \%{ }^{2}$. Meanwhile, milk powder especially from abroad is becoming highly welcomed among younger mothers, thus reducing the duration of breast-feeding. Is it largely because the cost of breast-feeding is higher or the perception on breast-feeding among people becomes different? This paper mainly focuses on the economic costs of breast-feeding, trying to find what mainly determines the duration of breast-feeding.

The paper is structured as follows: The next Section 2 summarizes the existing literature. Section 3 describes the data, definition of variables, and methodologies used. In Section 4, the author analyzes empirical result. Finally, some conclusions and policy implications are given in Section 5.

\section{LITERATURE REVIEW}

The main factors that influence breast-feeding can be categorized as two kinds. The first kind is socio-demographic factor which mainly contains age, marital status, education, and income level (McLeod, Pullon, and Cookson 2002). Forster, McLachlan, and Lumley (2006) conducted a randomized controlled trial in Australian women, finding that there was an increasing association with older maternal age. Colodro-Conde et al. (2011) studied the trends of breast-feeding in Spain from the 1960s to the end of the century to analyze the relationship between level of education and breast-feeding duration. Join point regression models for breast-feeding duration for the firstborn child throughout these years showed a U-shaped curve. However, the trend for women with primary studies showed a constant decrease throughout the whole period $(-7.4 \%)$, while higher education levels related to a positive trend from the 1970s onward (3.4\%). The authors concluded that in the Spanish context, maternal level of education was not associated with breast-feeding duration in the same direction or with the same magnitude across time. In the research conducted by Heck et al. (2006), women with higher family incomes, those who had or whose partners had higher education levels, and women who had or whose partners had professional or executive occupations were more likely than their counterparts to breast-feed. The second kind is biophysical factors, such as subjective breast-feeding, Lee and Ip (2008) found that the breast-feeding outcome was significantly related to the subjective breast-feeding efficacy. The subjective breast-feeding efficacy in women who can breast-feed for longer than one month is significantly higher than those who breast-feed for less than one month. DiGirolamo et al. (2005) found that early breast-feeding practices were also important factors. What is more, insufficient milk supply is one of the most common reasons why women give for breast-feeding cessation. Only about $5 \%$ of women actually have physiologic and real insufficient milk supply although up to $50 \%$ report that they have insufficient milk for their babies (Hector and King 2005).

Other factors, for example, child's gender, ethnicity, residence status, access to piped water, the attitude of her partner, maternity leave, and medical insurance will also affect mother's decision on breast-feeding. What is more, factors such as family support, psychosocial factors, or confidence of oneself also play an important role. There is evidence that low maternal breast-feeding confidence is associated with early cessation of breast-feeding. Although there are lots of researches on breast-feeding durations, most of them are from statistical view, for the left use models like probit or logit model which divide the duration for breast-feeding into two groups at the cutoff which is the average breast-feeding months. Also, very few studies were focused on China case. In this paper, duration models are applied to analyze the factors that affect duration of breast-feeding in Chinese women. 


\section{DATA AND VARIABLES}

The dataset is China Health and Nutrition Survey (CHNS) which covers about 4,400 households with a total of 26,000 individuals in nine provinces in 1989, 1991, 1993, 1997, 2000, 2004, 2006, and 2009. There are cross-section data from the eight years and the target people are women with the first child, who get married and are below 52 years old. Table 1 is a brief description and summary of all variables.

In this paper, breast-feeding is defined as a child feeding method where the child receives some breast milk but can also receive any food or liquid including non-human milk (Webb et al. 2002). The key variables are income for women and their husbands, since only those who have work can have regular wage every month. But for people in rural areas, the income mainly comes from farming, gardening, fishing, and raising poultry. So for those who do not have wage income, total home income is divided by the house members except for the old and children to estimate the income for them. Because the main focus is on economic opportunity costs, so income is narrowed to labor market income excluding the subsidy, welfare, and coupons. The working experience is defined as the time when working outside.

\section{ESTIMATION RESULTS}

When trying to find what factors affect the duration of breast-feeding among women, there are two main concerns about the data. First, the duration of breast-feeding can be truncated either by pregnancy or by the birth of another child or by the date of interview. If at the time of the interview the child is still being breast-fed, then it could not be known that how much longer this will continue. Second, it is a self-reported question, many mothers will not remember it so clearly especially in rural areas, there are recall error problems. So in order to solve right censoring problem, duration model is employed to analyze it. Survival analysis is used to examine the duration of breast-feeding as it provides a good understanding of breast-feeding behavior over time. In a regression using Cox's proportional hazards model, it allows joint estimation of the effects of predictor variables on the "hazard"- the risk of cessation of breast-feeding, rather than the duration itself, and can be used to analyze data that contain censored observations. The dependent variable is the duration of breast-feeding in month unit and the independent variables are income for both women and their husbands, age when women gave birth to their children, the age of women's husbands when being interviewed. The education levels are divided into seven groups according to the highest level attained, which are illiterate, primary school, junior school, senior school, technical or vocational school, undergraduate, and graduate. Also, there are two dummy variables which indicate whether the infant is a boy or not and in urban areas or not. The regression specification is as follows:

$$
\begin{aligned}
& y=\beta_{0}+\beta_{1} \cdot \text { age }+\beta_{2} \cdot \text { income }+\beta_{3} \cdot \text { educ }+ \\
& \beta_{4} \cdot \text { income_husband }+\beta_{5} \cdot \text { edu_husband }+ \\
& \beta_{6} \cdot \text { age_husband }+\beta_{7} \cdot \text { male }+\beta_{8} \cdot \text { urban }+\varepsilon
\end{aligned}
$$

From the pooled cross section data regression results as shown in Table 2, we can find that women's income has dramatic effect on the duration of breast-feeding behavior. One more unit of income will lower the duration by about $10 \%$. It is less likely for mothers who are of high income to breast-feed their children because the opportunity cost is so high. The same case happens for the income of their husbands. One unit higher income of their husbands will have about 9\% higher risk for cessation of breast-feeding, thus it has negative effect on duration. Because in most families, the income for husband is the main source of living expense and it appears to be the case that for parents who do not have enough time to take care of their children, buying expensive milk powder or hiring people to assist caring for their infants is a 
Table 1. Statistics Summary for Key Variables

\begin{tabular}{llll}
\hline Variable & Description of variables & Mean & Std. Dev. \\
\hline Bfduration & Number of months breast-feeding her child & 13.2 & 6.051 \\
Male & Dummy variable for child is male or female, 1 denotes male; otherwise is 0 & .539 & .499 \\
Urban & Dummy variable, urban = 1; rural = 0 & .291 & .454 \\
Wave & Interview years, eight waves from 1989 to 2009 & 1994 & 6.414 \\
Sch & Education level of women, six levels & 8.077 & 3.618 \\
Inc & Income of last year for women & 2,610 & 5,824 \\
Exp & Working experience for women, equals to age-sch-6 & 13.03 & 5.742 \\
Linc & Log form of income of last year for women & 7.28 & 1.443 \\
Age & Age when women give birth to their children & 28.66 & 5.698 \\
Inc_hus & Income of last year for women's husbands & 3,599 & 7,344 \\
Age_hus & Age when women's husbands in interview year & 31.09 & 6.041 \\
Sch_hus & Education level of women's husbands, six levels & 9.015 & 3.274 \\
Linc_hus & Log form of income of last year for women's husbands & 7.608 & 1.497 \\
Num children & Number of children living with the women & 1.619 & .778 \\
Maternity_leave & Dummy variable indicates whether women are on maternity leave or not, if yes & .0465 & .211 \\
\hline
\end{tabular}

Table 2. Regrssion Results for Pooled Cross Section Data

\begin{tabular}{|c|c|c|c|}
\hline & (1) & $(2)$ & (3) \\
\hline \multirow{2}{*}{ Variable } & Bfduration & Bfduration & Bfduration \\
\hline & Coefficient & Coefficient & Coefficient \\
\hline \multirow[t]{2}{*}{ Male } & -.11 & $-.293^{* * *}$ & $-.278^{* * *}$ \\
\hline & $(-1.53)$ & $(-3.20)$ & $(-2.98)$ \\
\hline \multirow[t]{2}{*}{ Linc } & $.0748^{*}$ & $.101^{* *}$ & $.135^{* * *}$ \\
\hline & -1.84 & -2.1 & -2.7 \\
\hline \multirow[t]{2}{*}{ Sch } & .0113 & .0125 & .0131 \\
\hline & -.87 & -.8 & -.84 \\
\hline \multirow[t]{2}{*}{ Exp } & $-.0814^{* * *}$ & $-.0820^{* * *}$ & $-.0655^{* *}$ \\
\hline & $(-3.62)$ & $(-2.92)$ & $(-2.35)$ \\
\hline \multirow[t]{2}{*}{ Age } & $.0461^{* *}$ & $.0498^{*}$ & .0363 \\
\hline & -2.03 & -1.76 & -1.31 \\
\hline \multirow[t]{2}{*}{ Sch_hus } & .00675 & .000656 & .00222 \\
\hline & -.38 & -.03 & -.1 \\
\hline \multirow[t]{2}{*}{ Linc_hus } & .016 & $.102^{* *}$ & $.0895^{*}$ \\
\hline & -.4 & -2.09 & -1.81 \\
\hline \multirow[t]{2}{*}{ Age_hus } & .00796 & -.00374 & .00169 \\
\hline & -.22 & $(-.08)$ & -.04 \\
\hline \multirow[t]{2}{*}{ Exp_hus } & .0146 & .00923 & .000272 \\
\hline & -.41 & -.2 & -.01 \\
\hline \multirow[t]{2}{*}{ Maternity_leave } & & $.890^{* * *}$ & $.882^{* * *}$ \\
\hline & & -4.13 & -4.07 \\
\hline \multirow[t]{2}{*}{ Num_children } & & & -.00123 \\
\hline & & & $(-.01)$ \\
\hline \multirow[t]{2}{*}{ _cons } & $-8.243^{* * *}$ & $-9.275^{* * *}$ & $-9.385^{* * *}$ \\
\hline & $(-13.39)$ & $(-11.57)$ & $(-11.48)$ \\
\hline \multirow[t]{2}{*}{ ln_sig } & $.947^{* * *}$ & $1.041^{* * *}$ & $1.051^{* * *}$ \\
\hline & -35.36 & -31.37 & -30.9 \\
\hline$N$ & 810 & 527 & 506 \\
\hline
\end{tabular}

Notes: $t$ statistics in parentheses. ${ }^{*} p<.10,{ }^{* *} p<.05,{ }^{* * *} p<.01$. All the regressions control for time variables. 
good choice. But for women who have more working experiences, it is more likely to have longer duration for their infants. It may be because women who work longer outside will be more likely to be informed of the benefits of breast-feeding or witness more successful cases from their colleagues or others, thus having positive effect on their behaviors. And the age of mother has significantly negative effect on duration of her child. Women who are one year older will have about $4 \%$ lower probability of breast-feeding. It seems like that the self-efficacy for older mom is less than younger mom, so they reduce the duration of breast-feeding, choosing milk powder to be an alternative. Figure 1 depicts such trend with the age of mother that is 50 and 28 separately. What is more, when adding information about whether the woman is on maternity leave or not, we can find that women who are on maternity leave have about $88 \%$ lower probability than mothers who are not. Since the average mandate maternity leave for Chinese women is six months, so moms need to return to work and cease the duration. When focusing on the gender of infant, we find strong evidence that the probability of breast-feeding a boy is on average $28 \%$ higher than a girl. Perhaps due to Chinese traditional perspective, boys are being paid more attention than girls. For mother who has more than one child, there may be much time spent on taking care of her children, although the coefficient of number of children living with her is not statistically significant, it can tell us that women have more children will have lower probability of breast-feeding their own children.

Second, because the proportion of not having information of income is about $30.28 \%$ and $30.03 \%$ for women and men respectively. So we can divide them into four groups, people below $50 \%$ percentile of income distribution are defined as low income group (for women is between 0-597 RMB, for their husbands is between $0-849 \mathrm{RMB}$ ), people above $75 \%$ percentile of income distribution are defined as high income group (for women is higher than 2,781 RMB, for their husbands is higher than 4,490 RMB), and people between them are defined as middle income group (for women is between 597 RMB-2,781 RMB, for their husbands is 849 RMB-4,490 RMB) ${ }^{3}$. People who we do not have information about their income are defined as NA income group. Middle income group is chosen as reference group.

From the previous regression, it seems like that the education level of women and their husbands has not much effect on the duration of breast-feeding, is it really the case or not? Since we neglect those people whose income information is missing, there arises sample-selection problem. For people who have income information, they are better off so that the education level may not be so much important because they can afford their children milk powder. But for the poorer people, the price of milk powder may affect their decisions on it. Then a regression with different income group is implemented as shown in Table 3. For women, the missing income group has $44.3 \%$ lower probability of risk which ceases the duration compared with middle income, while for men, the missing income group has $43.3 \%$ lower probability of risk which ceases the duration compared with middle income. It shows that for low-income families, they will choose to breast-feed their children for economic situation. For mothers with high level of education, they have a lower probability to breast-feed. Women who have higher level of education can get higher position in labor market and earn more. Since there is high opportunity cost, they have to shorten duration for breast-feeding. A more clear trend can be found from Figure 2 comparing the high and low income of women. Mothers who have one more year of education will have $3.70 \%$ lower of probability to breast-feed their children. When comparing 16 with six years of schooling, the survivial function is steeper for bettter education mother (see Figure 3). But for the education level for their husbands, it does not show 
Table 3. Regression Results by Income Distribution

\begin{tabular}{|c|c|c|}
\hline & $(1)$ & $(2)$ \\
\hline \multirow{2}{*}{ Variable } & Bfduration & Bfduration \\
\hline & Coefficient & Coefficient \\
\hline \multirow[t]{2}{*}{ Male } & -.0815 & -.0859 \\
\hline & $(-1.37)$ & $(-1.45)$ \\
\hline \multirow[t]{2}{*}{ Inc_missing } & $-.443^{* * *}$ & \\
\hline & $(-3.34)$ & \\
\hline \multirow[t]{2}{*}{ Inc_high } & .0758 & \\
\hline & -.77 & \\
\hline \multirow[t]{2}{*}{ Inc_low } & -.00908 & \\
\hline & $(-.08)$ & \\
\hline \multirow[t]{2}{*}{ Age } & $-.0332^{* * *}$ & $-.0332^{* * *}$ \\
\hline & $(-3.23)$ & $(-3.22)$ \\
\hline \multirow[t]{2}{*}{ Sch } & $.0369^{* * *}$ & $.0382^{* * *}$ \\
\hline & -3.66 & -3.81 \\
\hline \multirow[t]{2}{*}{ Inc_hus } & $2.59 \mathrm{E}-06$ & \\
\hline & -.47 & \\
\hline \multirow[t]{2}{*}{ Age_hus } & $.0225^{* *}$ & $.0227^{* *}$ \\
\hline & -2.44 & -2.47 \\
\hline \multirow[t]{2}{*}{ Sch_hus } & -.00134 & -.00149 \\
\hline & $(-.13)$ & $(-.14)$ \\
\hline \multirow[t]{2}{*}{ Urban } & $.223^{* * *}$ & $.232^{* * *}$ \\
\hline & -3.21 & -3.34 \\
\hline \multirow[t]{2}{*}{ Inc_hus_missing } & & $-.433^{* * *}$ \\
\hline & & $(-3.25)$ \\
\hline \multirow[t]{2}{*}{ Inc_hus_high } & & .0606 \\
\hline & & -.61 \\
\hline \multirow[t]{2}{*}{ Inc_hus_low } & & -.0272 \\
\hline & & $(-.25)$ \\
\hline \multirow[t]{2}{*}{ Inc } & & -.00013 \\
\hline & & $(-.35)$ \\
\hline \multirow[t]{2}{*}{ _cons } & $-6.725^{* * *}$ & $-6.732^{* * *}$ \\
\hline & $(-23.30)$ & $(-23.06)$ \\
\hline $\ln \_p$ & $.915^{* * *}$ & $.913^{* * *}$ \\
\hline ln_sig & -41.34 & -41.29 \\
\hline$N$ & 1,175 & 1,175 \\
\hline
\end{tabular}

Notes: $t$ statistics in parentheses. ${ }^{*} p<.10,{ }^{* *} p<.05,{ }^{* * *} p<.01$. All the regressions control for time variables.

significant effect. When their husbands are getting older, the probability for women to breast-feed is $2.27 \%$ lower, which shows the same direction but is not so much important than women themselves. After adding the dummy variable which denotes that the women live in urban or rural areas, the effect is significantly different. Women who live in urban areas have relative shorter duration of breast-feeding than rural women. The $p$-value for log-rank test for testing the survival function is identical with .000 , which is strong evidence that the breast-feeding duration is significantly different between urban and rural areas. It can be shown from Figure 4 about Weibulll distribution by urban and rural. 


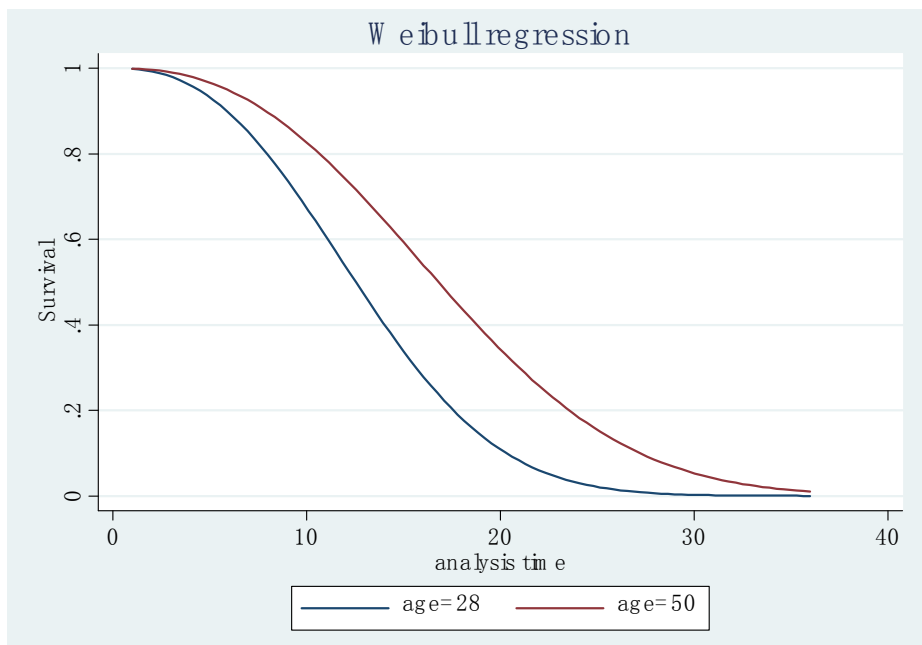

Figure 1. Weibull Regression With Different Age for Women.

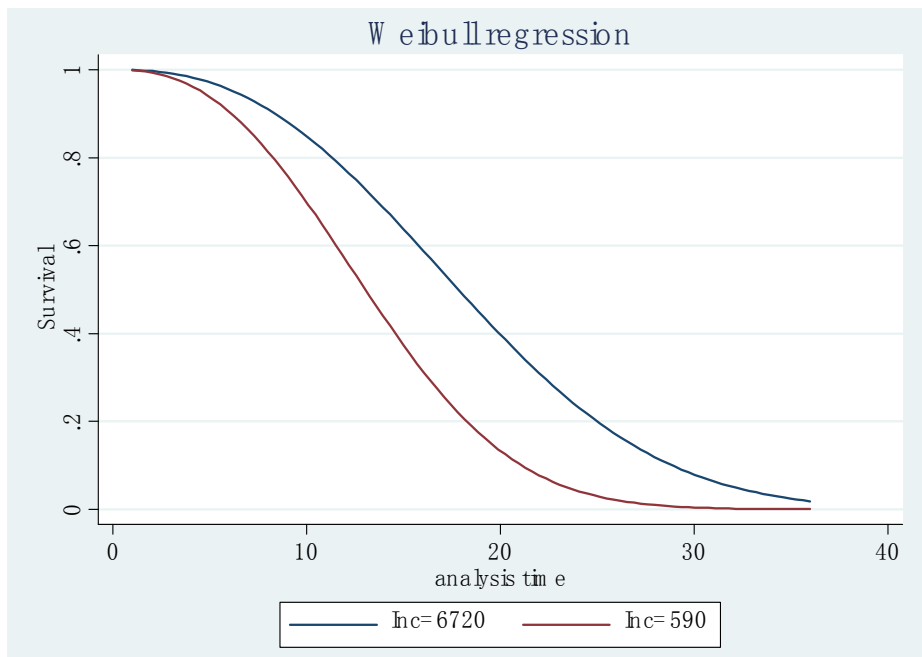

Figure 2. Weibull Regression With Different Income for Women.

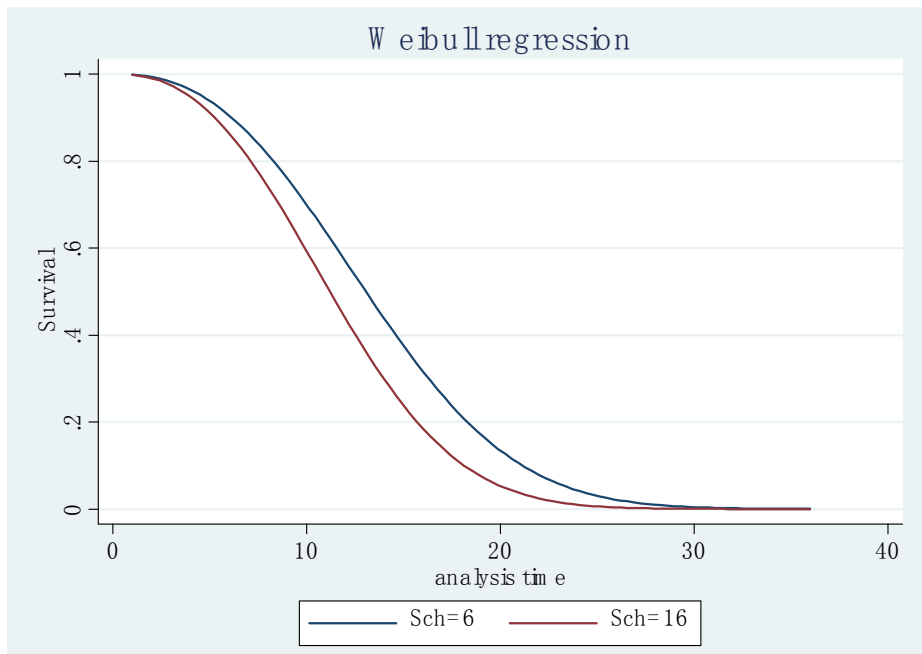

Figure 3. Weibull Regression With Different Education for Women. 


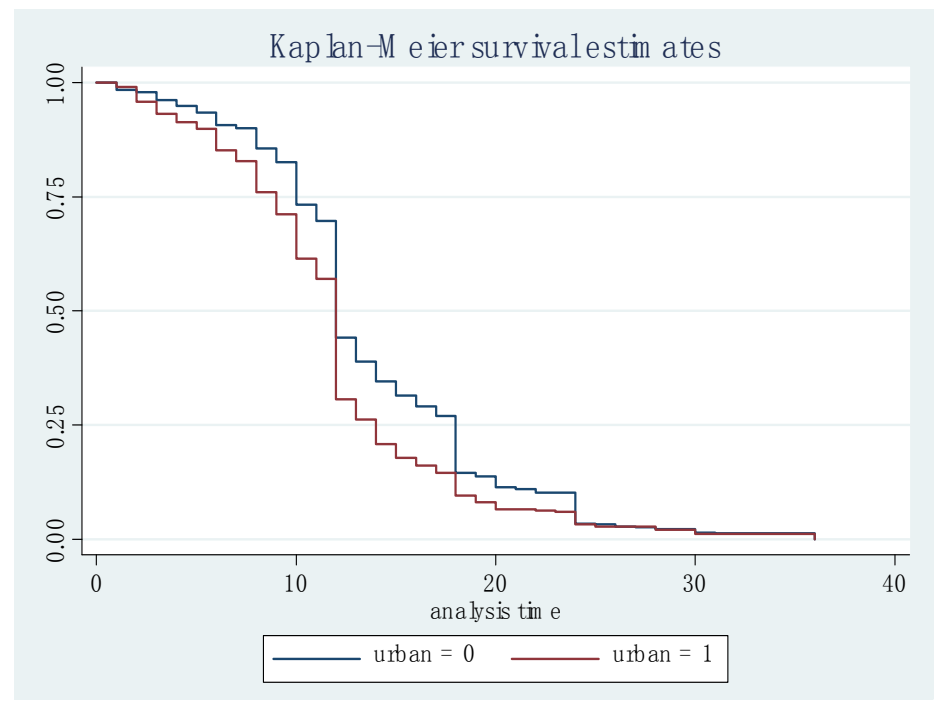

Figure 4. Survival Function for Urban and Rural.

\section{CONCLUSIONS}

From the CHNS cross-sectional data applied with duration models, we can find the main determinants of breast-feeding among women in China. Families with higher income will have shorter duration of their children especially with mothers. The duration of breast-feeding will decrease with the aging of mother and father. And women who have higher education level will not have so much time compared with the lower level mothers. Mothers with more working experiences have longer duration of breast-feeding. All the results show that the opportunity cost for women especially in urban areas is so high that they have to shorten the duration of breast-feeding their children. But no matter in urban or rural areas, boys capture more attention than girls since the duration for them is higher than girls from the regression results.

\section{Notes}

1. Retrieved (http://www.who.int/mediacentre/news/releases/20 13/world_breastfeeding_week_20130730/en/).

2. Retrieved (http://health.people.com.cn/n1/2016/0802/c39800 4-28605135.html).

3. There is no information about income below $25 \%$ percentile.

\section{References}

Borra, C., M. Iacovou, and A. Sevilla. 2012. "The Effect of Breastfeeding on Children's Cognitive and Noncognitive Development." Labour Economics 19(4):496-515.

Colodro-Conde, L., J. F. Sánchez-Romera, M. J. Tornero-Gómez, F. Pérez-Riquelme, M. Polo-Tomás, and J. R. Ordoñana. 2011. "Relationship Between Level of Education and Breastfeeding Duration Depends on Social Context Breastfeeding Trends Over a 40-year Period in Spain.” Journal of Human Lactation 27(3):272-278.

DiGirolamo, A., N. Thompson, R. Martorell, S. Fein, and L. Grummer-Strawn. 2005. "Intention or Experience? Predictors of Continued Breastfeeding." Health Education \& Behavior 32(2):208-226.

Forster, D. A., H. L. McLachlan, and J. Lumley. 2006. "Factors Associated With Breastfeeding at Six Months Postpartum in a Group of Australian Women." International Breastfeeding Journal 1(1):1.

Heck, K. E., P. Braveman, C. Cubbin, G. F. Chávez, J. L. Kiely, and G. F. Chárez. 2006. "Socioeconomic Status and Breastfeeding Initiation Among California Mothers." Public Health Reports 121(1):51-59.

Hector, D. and L. King. 2005. "Interventions to Encourage and Support Breastfeeding." New South Wales Public Health Bulletin 16(4):56-61.

Lee, C. Y. and W. Y. Ip. 2008. "The Efficacy of Breastfeeding in Chinese Women With Different Intrapartum Experiences: A Hong Kong Study." Hong Kong Journal of Gynecology, Obstetrics and Midwifery 8:13-17.

McLeod, D., S. Pullon, and T. Cookson. 2002. "Factors 
Influencing Continuation of Breastfeeding in a Cohort of Women." Journal of Human Lactation 18(4):335-343.

Mihrshahi, S., R. Ampon, K. Webb, C. Almqvist, A. S. Kemp, D. Hector, and G. B. Marks. 2007. "The Association Between Infant Feeding Practices and Subsequent Atopy Among Children With a Family History of Asthma." Clinical \& Experimental Allergy 37(5):671-679.

Webb, K., K. Marks, M. Lund-Adams, and B. Abraham. 2002. Towards a National System for Monitoring Breastfeeding in Australia: Recommendations Forpopulation Indicators, Definitions and Next Steps. Canberra: Australian Food and
Nutrition Monitoring Unit, Commonwealth Department of Health and Aged Care.

\section{Bio}

Junzi He, Ph.D. candidate, research assistant, China Center for Human Capital and Labor Market Research, Central University of Finance and Economics, Beijing, China; research fields: labor economics, micro econometrics, education economics. 